\title{
MODEL OF USAHA KESEHATAN SEKOLAH PELANGI (UKSP) ON CHILDREN ORAL HEALTH STATUS
}

\author{
Bedjo Santoso; Lanny Sunarjo; Boby Irsan Sakbana \\ Email: bedjosantoso27@gmail.com
} \begin{abstract}
improving children's dental and oral health status. oral health status.

\section{PENDAHULUAN}

Pembangunan kesehatan bertujuan untuk meningkatkan kesadaran, kemauan dan kemampuan hidup sehat bagi setiap orang agar terwujud derajat kesehatan masyarakat yang setinggi-tingginya. Upaya pelayanan kesehatan dilakukan melalui pendekatan promotif, preventif, kuratif, dan rehabilitatif baik secara perseorangan maupun masyarakat yang dilaksanakan secara terpadu, menyeluruh dan berkesinambungan, tetapi dalam pembangunan kesehatan masih terjadi masalah khususnya masalah kesehatan pada anak sekolah dasar ${ }^{1}$.

Masalah kesehatan yang terjadi pada anak sekolah dasar khususnya penyakit gigi dan mulut di Asia Tenggara tahun 2015 sebesar $35 \%$. Upaya yang telah dilakukan oleh negara-negara itu dalam mengatasi
\end{abstract}

ABSTRACT

Health development aims to improve community health status, but in health development there are still problems, especially health problems in elementary school children. Efforts made by the government in the form of the School Health Effort program and the success rate in each province averaged $13.6 \%$, so a comprehensive model is needed in the school named the Model of Usaha Kesehatan Sekolah Pelangi. The aims is to produce the Model of Usaha Kesehatan Sekolah Pelangi in improving health status of children's dental and oral health status.

In this research used Research and Development, there are five stages of research namely: information gathering, model design, expert validation and revision, model testing (using the quasiexperimental control group pretest and posttest design method and model results). The sample was divided into 2 groups namely the implementation of the Model of Usaha Kesehatan Sekolah Pelangi in the intervention group and the school health business program in the control group. Data were tested using intraclass correlation coefficient, chi-square, shapiro wilk, friedman, wilcoxon and mann-whitney.

The results showed the school health business model is feasible as a model of education and health services shown with the value of $\mathrm{p}<0.031$. The Model of Usaha Kesehatan Sekolah Pelangi is effective in increasing the performance treatment index (PTI) shown by the value of $p<0.001$ and decreasing the simplified oral hygiene index (OHI-S) indicated by the value of $\mathrm{p}<0.001$.

The conclusion of this research is Model of Usaha Kesehatan Sekolah Pelangi is effective in

Keywords: Primary school children, Model of Usaha Kesehatan Sekolah Pelangi, Children's dental and

masalah tersebut melalui promosi kesehatan gigi dan mulut keseluruh anak sekolah dasar di Asia Tenggara tahun 2015. asalah kesehatan pada anak sekolah dasar di Indonesia tahun 2018 diketahui penyakit gigi dan mulut sebesar 57,6\%. Data ini menunjukan masalah kesehatan anak usia sekolah dasar di Indonesia termasuk dalam kategori tinggi bila dibandingkan dengan target nasional. Perbandingan antara masalah kesehatan anak sekolah dasar dengan target nasional sangat berbeda sehingga diperlukan suatu solusi dari berbagai pihak baik pemerintah maupun swasta dan masyarakat dalam menangani masalah tersebut ${ }^{2,3}$.

Upaya yang dilakukan pada anak sekolah dasar melalui program Usaha Kesehatan Sekolah (UKS) dalam meningkatkan derajat kesehatan anak sekolah guna menunjang prestasi belajar anak usia sekolah setinggi-tingginya ${ }^{4,5}$. Hasil penelitian sebelumnya telah membuktikan 
hubungan bermakna antara pelaksanaan program UKS dengan Perilaku Hidup Bersih dan Sehat (PHBS) dan adanya hubungan bermakna antara pelaksanaan program UKS dalam upaya meningkatkan derajat kesehatan pada anak usia sekolah dasar ${ }^{6},{ }^{7}$.

Tingkat keberhasilan pelaksanaan program UKS di setiap provinsi antara lain $13,6 \%$, hal ini menunjukan presentasi ketercapaian masih rendah karena disebabkan oleh beberapa kendala antara lain, SDM, sumber dana dan sarana-prasarana UKS yang belum memadai. Adapun penelitian sebelumnya membuktikan bahwa $84,8 \%$ sekolah belum ada ruang UKS, 57,6\% sekolah tidak mempunyai lemari obat sebesar $78,8 \%$, sekolah tidak memiliki tempat cuci tangan atau wastafel 87,9\%, sekolah belum ada program kerja UKS, dan $84,8 \%$ sekolah tidak ada pertanggung jawaban dalam pelaksanaan program TRIAS UKS ${ }^{8,9}$.

Upaya dalam mengatasi masalah yang terjadi pada pelaksanan program UKS tersebut, diperlukan model komprehensif di sekolah yang mampu memberikan pendidikan dan pelayanan kesahatan umum, kesehatan gigi dan mulut serta gizi dan ditangani secara langsung oleh tenaga terapis gigi dan mulut. Tujuan dari pelayanan komprehensif di sekolah yaitu meningkatkan derajat kesehatan anak sekolah dasar, melaksanakan pendidikan kesehatan dan pelayanan kesehatan di sekolah, mengurangi absensi siswa. Adapun manfaat pelayanan kesehatan secara komprehensif antara lain memberikan pelayanan kesehatan secara langsung, askes pelayanan kesehatan lebih dekat, mengurangi masalah kesehatan yang terjadi pada anak usia sekolah dasar ${ }^{4}$.

Pelayanan kesehatan komprehensif yang telah dilaksanakan di Pakistan berupa program sekolah sehat dengan bentuk kegiatan yang dilakukan sebagai berikut: pelatihan untuk melakukan penjaringan pada anak sekolah untuk mengetahui kesehatan gigi dan mulut. Hasil dari program sekolah sehat di Pakistan pada 86 juta anak usia sekolah dasar pada tahun 2010 diketahui masalah kesehatan gigi dan mulut sebesar $5,02 \%{ }^{10}$. Sedangkan model pelayanan kesehatan komprehensif yang akan dilaksanakan oleh peneliti diberi nama Usaha Kesehatan Sekolah Pelangi (UKSP). Perbedaan antara UKS dan Usaha Kesehatan Sekolah Pelangi yaitu pelayanan kesehatan yang dilakukan tenaga yang dibantu oleh dokter kecil dan guru UKS di Sekolah Dasar (SD) setiap 6 bulan sekali, sedangkan Usaha Kesehatan Sekolah Pelangi kegiatan yang dilakukan berupa, pendidikan dan palayanan kesehatan di SD setiap hari oleh tenaga kesehatan. Model Usaha Kesehatan Sekolah Pelangi diharapkan dapat meningkatkan status kesehatan umum, kesehatan gigi dan mulut serta gizi anak sekolah dasar.

\section{METODE PENELITIAN}

Metode yang digunakan adalah Research and Development (R\&D). Penelitian ini bertujuan membuat model Usaha Kesehatan Sekolah Pelangi yang dilaksanakan dengan kegiatan pendidikan kesehatan dan pelayanan kesehatan. Metode $\mathrm{R}$ \& D merupakan salah satu proses penelitian dalam mengembangkan suatu produk baru atau menyempurnakan produk yang telah ada dan dapat dipertanggung jawabkan. Prosedur penelitian dan pengembangan meliputi 5 langkah utama antara lain pengumpulan informasi, rancang bangun produk atau model, validisi ahli dan revisi, uji coba produk atau model dan hasil produk atau model ${ }^{11-13}$.

Pengukuran pengetahuan, sikap dan keterampilan tenaga kesehatan tentang model Usaha Kesehatan Sekolah Pelangi selama 15 hari dengan kegiatan sebagai berikut: pretest, pelatihan tenaga kesehatan dan post-test. Pada anak sekolah dasar selama dilakukan intervensi selama 1 bulan dengan rincian kegiatan sebagai berikut : pre-test, intervensi dan post-test.

\section{HASIL DAN PEMBAHASAN}

1. Pengumpulan Informasi pelaksanaan program UKS dalam meningkatkan derajat kesehatan anak antara lain:

a. Waktu palayanan yang diberikan harus kontinyu \&berkesinambungan 
b. Sarana-prasarana yang memadai.

c. Perlu dukungan dari semua warga sekolah

d. Adanya kolaborasi tenaga keperawatan, terapis gigi dan mulut dan ahli gizi sehingga perlu sebuah inovasi berupa pengembangan program UKS menjadi model Usaha Kesehatan Sekolah Pelangi (UKSP) Tenaga kesehatan selalu ada di sekolah dalam memberikan promosi dan pelayanan kesehatan.Rancang bangun

2. Rancang Bangun Model

Berdasarkan hasil pengumpulan informasi dirancang sebuah model Usaha Kesehatan Sekolah Pelangi. Usaha Kesehatan Sekolah Pelangi merupakan upaya pengembangan kesehatan dalam meningkatkan derajat kesehatan anak sekolah dasar.

3. Validasi Ahli

Hasil validitas ahli menunjukan bahwa model Usaha Kesehatan Sekolah Pelangi layak dalam pelaksanaan Usaha Kesehatan Sekolah Pelangi.

4. Uji Coba Produk

Tabel 1. Data karakteristik anak SD pada kelompok intervensi dan kontrol.

\begin{tabular}{|c|c|c|c|c|c|c|}
\hline No & Variebe & \multicolumn{2}{|c|}{ Intervensi } & \multicolumn{2}{|c|}{ Kontrol } & \multirow[t]{2}{*}{ Nilai $P^{*}$} \\
\hline & & $\overline{\mathrm{N}}$ & $\%$ & $\overline{\mathrm{N}}$ & $\%$ & \\
\hline \multicolumn{7}{|c|}{ 1. Umur } \\
\hline & $\leq 9$ Tahun & 15 & 42.9 & 18 & 51.4 & \multirow{2}{*}{0.431} \\
\hline & $\geq 10$ Tahun & 20 & 57.1 & 17 & 48.6 & \\
\hline \multicolumn{7}{|c|}{ 2. Jenis Kelamin } \\
\hline & Laki-laki & 18 & 51.4 & 19 & 54.3 & \multirow{2}{*}{1.000} \\
\hline & Perempuan & 17 & 48.6 & 16 & 45.7 & \\
\hline \multicolumn{7}{|c|}{ 3. Pekerjaan orang Tua } \\
\hline & PNS & 2 & & 1 & 3 & \multirow{3}{*}{0.905} \\
\hline & TNI & 1 & & 0 & 0 & \\
\hline & SWASTA & 32 & & 34 & 97 & \\
\hline \multicolumn{7}{|c|}{ 4. Status Sekolah } \\
\hline & Negeri & 1 & 100 & 1 & 100 & \multirow[b]{2}{*}{1.000} \\
\hline & Swasta & 0 & 0 & 0 & 0 & \\
\hline
\end{tabular}

$\therefore *$ Chi square

Berdasarkan tabel diatas diketahui distribusi frekuensi anak sekolah dasar menurut umur, prosentase paling besar adalah $51.7 \%$ (20 anak) berusia $>10$ tahun. Frekuensi anak sekolah dasar berdasarkan jenis kelamin, prosentase paling besar adalah 54.3 (19 anak) laki-laki. Hasil uji homogenitas berdasarkan frekuensi umur dan jenis kelamin anak menunjukan bahwa nilai $p$-value $>0.05$, sehingga dapat disimpulkan bahwa varian dari dua kelompok sampel adalah sama.

Hasil uji normalitas menunjukan bahwa PTI dan OHI-S pada kelompok intervensi dan kontrol berdistribusi tidak normal nilai $p$ value $<0.05$, sehingga dapat diambil kesimpulan bahwa data berdistribusi tidak normal maka dilanjutkan uji nonparametrik.

Hasil uji PTI menunjukan p-value kelompok intervensi adalah 0,000 $\mathrm{p}<0.05$ artinya model Usaha Kesehatan Sekolah Pelangi efektif meningkatkan PTI, nilai $p$ value kelompok kontrol adalah 0.368 $\mathrm{p}>0.05$ ) artinya program UKS tidak efektif meningkatkan PTI.

Hasil Post Hoc data berpasangan menunjukan bahwa nilai PTI anak sekolah dasar pada pretest-posttest 1 mengalami peningkatan, signifikan terbukti pada kelompok intervensi nilai p-value 0.001 ( $>0.05$ ) sedangkan kelompok kontrol tidak mengalami peningkatan dilihat dari nilai $p$ value 0.317 ( $\mathrm{p}>0.05$ ). Nilai PTI anak sekolah dasar pada posttest 1-posttest 2 tidak mengalami peningkatan signifikan, terbukti pada kelompok intervensi nilai $p$-value 0.083 ( $>>0.05$ ) dan kelompok kontrol nilai $p$-value 1.000 ( $p>0.05$ ). Nilai PTI anak sekolah dasar pada pretest-posttest 2 mengalami peningkatan signifikan pada kelompok intervensi terbukti nilai $p$-value 0.001 $(\mathrm{p}<0.05)$ sedangkan kelompok kontrol tidak mengalami peningkatan, dilihat dari nilai $p$ value 0.317 ( $\mathrm{p}>0.05)$.

Hasil uji efektivitas data tidak berpasangan nilai post-test 1 dan post-test 2 bermakna secara signifikan masing-masing nilai $p$-value 0.001 dan $0.001(\mathrm{p}>0.05)$ dan dilakukan uji lanjut untuk mengetahui nilai perubahan $(\Delta)$ prostest 1-postest 2 tidak bermakna secara signifikan terbukti dengan hasil $p$-value 0.079 ( $\mathrm{p}>0.05)$ namum pada pretest-posttest 1 dan pretest-posttest 2 bermakna secara signifikan dilihat dari masing-masing nilai $p$-value $0.001(\mathrm{p}<0.05)$ yang artinya model Usaha Kesehatan Sekolah Pelangi efektif meningkatkan PTI anak dibandingkan dengan program UKS. 
a. Uji Efektivitas OHI-S

Tabel 2. Hasil uji efektivitas OHI-S

kelompok intervensi dan kelompok kontrol

\begin{tabular}{|c|c|c|c|c|}
\hline $\begin{array}{c}\text { Variabel dan } \\
\text { kelompok }\end{array}$ & Mean \pm SD Pretest & Mean \pm SD Postetst 1 & Mean \pm SD Postetst2 & $p$-value \\
\hline \multicolumn{5}{|c|}{ Uji Berpasangan* } \\
\hline Intervensi & $2.657+1.0514$ & $0.989+0.8134$ & $0.594+0.6821$ & 0.001 \\
\hline Kontrol & $2.923+0.9397$ & $2.923+0.9412$ & $2.894+0.9242$ & 0.246 \\
\hline \multicolumn{5}{|c|}{ Uji Post Hoc Berpasangan** } \\
\hline & Pretest Posttest1 & Pretest 1-Posttest2 & Pretest Posttest2 & \\
\hline & p-value & p-value & p-value & \\
\hline Intervensi & 0.001 & 0.001 & 0.001 & \\
\hline Kontrol & 1.00 & 0.175 & 0.194 & \\
\hline \multicolumn{5}{|c|}{ Uji Tidak Berpasangan Data Post-Test Kelompok Intervensi dan Kontrol*** } \\
\hline & \multicolumn{2}{|c|}{ Posttest1 } & \multicolumn{2}{|l|}{ Posttest2 } \\
\hline p-value & \multicolumn{2}{|c|}{0.001} & \multicolumn{2}{|l|}{0.001} \\
\hline \multicolumn{5}{|c|}{ Uji Tidak Berpasangan Nilai Perubahan $\left(\Delta \mathrm{j}^{* * *}\right.$} \\
\hline \multirow[b]{2}{*}{ Intervensi } & Pretest Posttest1 & Pretest 1-Posttest2 & \multicolumn{2}{|l|}{ Pretest Posttest2 } \\
\hline & $1.669 \pm 0.769$ & $0.394 \pm 0.584$ & $2.063 \pm 0.8918$ & \\
\hline Kontrol & $0.000 \pm 0.243$ & $0.029 \pm 0.1152$ & $0.029 \pm 8.4515$ & \\
\hline p-value & 0.001 & 0.005 & 0.001 & \\
\hline
\end{tabular}

Hasil uji OHI-S menunjukan p-value kelompok intervensi adalah $0.000(\mathrm{p}<0.05)$ artinya model Usaha Kesehatan Sekolah Pelangi efektif menurunkan OHI-S, nilai $p$ value kelompok kontrol adalah 0.246 ( $>0.05)$ artinya program UKS efektif menurunkan OHI-S.

Hasil Post Hoc data berpasangan menunjukan bahwa nilai OHI-S anak sekolah dasar pada pretest-posttest 1 mengalami penurunan, signifikan terbukti pada kelompok intervensi nilai $p$-value 0.001 ( $>>0.05$ ) sedangkan kelompok kontrol tidak mengalami penurunan dilihat dari nilai $p$ value $1.000 \quad(\mathrm{p}>0.05)$. Nilai OHI-S anak sekolah dasar pada posttest 1-posttest 2 mengalami penurunan signifikan, terbukti pada kelompok intervensi nilai $p$-value 0.001 $(\mathrm{p}<0.05)$ sedangkan kelompok kontrol tidak mengalami penurunan dilihat dari nilai $\mathrm{p}$ value $0.175(\mathrm{p}>0.05)$. Nilai OHI-S anak sekolah dasar pada pretest-posttest 2 mengalami penurunan signifikan pada kelompok intervensi terbukti nilai $p$-value $0.001(\mathrm{p}<0.05)$ sedangkan kelompok kontrol tidak mengalami penurunan signifikan, dilihat dari nilai $p$-value 0.194 ( $\mathrm{p}>0.05)$.

Hasil uji efektivitas data tidak berpasangan nilai post-test 1 dan post-test 2 bermakna secara signifikan masing-masing nilai $p$-value 0.001 dan 0.001 ( $\mathrm{p}>0.05)$ dan dilakukan uji lanjut untuk mengetahui nilai perubahan $(\Delta)$ pretest-posttest 1 , prosttest 1posttest 2 , pretest-posttest 2 bermakna secara signifikan masing-masing nilai $p$-value $0.001,0.005$ dan $0.001(\mathrm{p}<0.05)$ yang artinya model Usaha Kesehatan Sekolah Pelangi efktif menurunkan OHIS-S anak sekolah dasar dibandingkan program UKS.

\section{PEMBAHASAN}

1) Model Usaha kesehatan sekolah Pelangi Model Usaha Kesehatan Sekolah Pelangi diimplementasikan melalui pendidikan dan pelayanan. Pendidikan kesehatan merupakan proses belajar untuk memperoleh ilmu pengetahuan, dan penanaman nilai sikap positif tentang cara memilihara diri sendiri agar tetap sehat ${ }^{14}$. Pelayanan kesehatan yang dilakukan pada anak usia sekolah melalui upaya promotif dan preventif ${ }^{15}$.

2) Efektivitas Model Usaha Kesehatan Sekolah Pelangi terhadap status kesehatan gigi dan mulut anak sekolah dasar.

Hasil penelitian menunjukan bahwa model Usaha Kesehatan Sekolah Pelangi efektif meningkatkan PTI anak terlihat nilai $p$-value $=0.001$. Performance Treatmment Index (PTI) merupakan indikator yang digunakan untuk mengetahui jumlah gigi 
permanen yang sudah dilakukan penambalan pada gigi yang berkaries. PTI merupakan indikator penilaian yang dapat menggambarkan motivasi seseorang untuk menumpat giginya yang mengalami karies dan sebagai upaya mempertahan gigi permanen ${ }^{16}$. Hal ini sesuai dengan meningkatkan tindakan kuratif sederhana pada anak sekolah dasar dapat meningkatkan derajat kesehatan anak ${ }^{17}$.

Hasil penelitian menunjukan bahwa adanya perbedaan antara model Usaha Kesehatan Sekolah Pelangi dengan program UKS dalam meningkatkan PTI anak, terlihat dari post-test 1 nilai $p$-value $=0.001$ dan posttest 2 nilai $p$-value $=0.001$. hal ini dikarenakan kelebihan model Usaha Kesehatan Sekolah Pelangi dapat memberikan pendidikan tentang pemeliharaan kesehatan gigi dan mulut serta penyakit gigi dan mulut. Pelayanan kesehatan gigi dan mulut yang dilakukan di Sekolah berupa pemeriksaan gigi dan mulut serta tindakan penambalan pada gigi yang berlubang dibandingkan dengan program UKS kegiatan yang dilakukan berupa promosi kesehatan tanpa melakukan pelayanan, hal ini sesuai dengan pelayanan kesehatan gigi dan mulut yang dilaksanakan di Sekolah dapat meningkatkan derajat kesehatan gigi dan mulut anak_ ${ }^{18}$.

Hasil penelitian menunjukan bahwa model Usaha Kesehatan Sekolah Pelangi efektif menurunkan OHI-S anak terlihat nilai $p$-value $=0.000$. OHI-S dapat menurun karena anak sekolah dasar telah diberikan pendidikan tentang cara menggosok gigi yang baik dan benar dengan metode demonstrasi, sehingga anak mampu mempraktekan sacara baik dan benar serta pelayanan yang diberikan berupa pembersihan karang gigi, pendidikan kesehatan berupa penyuluhan cara menggosok gigi yang baik dan benar menggunakan metode demonstrasi efektif untuk menurunkan angka OHI-S anak ${ }^{19}$.

Hasil penelitian menunjukan bahwa adanya perbedaan antara model Usaha Kesehatan Sekolah Pelangi dengan program UKS efektif menurunkan OHI-S anak, terlihat pada post-test 1 nilai $p$-value $=0.001$ dan post-test 2 nalai $p$-value $=0.001$. Hal ini dikarenakan kelebihan model Usaha Kesehatan Sekolah Pelangi memberikan pendidikan dan pelayanan kesehatan yang dilakukan di Sekolah berupa sikat gigi bersama dan pembersihan karang gigi dibandingkan program UKS kegiatan yang dilakukan berupa promosi kesehatan. Hal ini sesuai dengan perbedaan indeks OHI-S pada anak sekolah dasar yang mendapat pelayanan kesehatan gigi dan mulut memiliki indeks OHI-S lebih rendah dibandingkan anak sekolah dasar yang tidak mendapat pelayanan kesehatan kesehatan gigi dan mulut ${ }^{20}$.

\section{SIMPULAN DAN SARAN}

Berdasarkan hasil penelitian, dapat disimpulkan bahwa model Usaha Kesehatan Sekolah Pelangi layak sebagai model dalam meningkatkan status kesehatan anak sekolah dasar, hal ini dapat diketahui sebagai berikut:

Modul Usaha Kesehatan Sekolah Pelangi layak sebagai pedoman dalam melaksanakan pendidikan dan pelayanan kesehatan anak sekolah dasar. Model Usaha Kesehatan Sekolah Pelangi efektif terhadap Performance Treatmment Index (PTI). Model Usaha Kesehatan Sekolah Pelangi efektif terhadap Oral Hygiene Index (OHIS).

Institusi sekolah dasar diharapakn menjalin kerja sama dengan tenaga kesehatan yang bekerja di pemerintahan atau swasta dalam menerapkan model Usaha Kesehatan Sekolah Pelangi, sebagai upaya peningkatan status kesehatan gigi dan mulut anak sekolah dasar.

Institusi akademik diharapakn melakukan penelitian lebih lanjut menganai model Usaha Kesehatan Sekolah Pelangi dengan menggunakan media pendidikan kesahatan yang berbeda, guna mengetahui kemampuan anak dalam meningkatkan status kesehatan gigi dan mulut anak. Peneliti selanjutnya dapat melakukan penelitian dengan metode yang berbeda, mengembangkan variabel penelitian dan waktu penelitian lebih dari 1 bulan, sehingga diperoleh hasil penelitian yang lebih akurat. 


\section{DAFTAR PUSTAKA}

1. Presiden R. Undang-Undang Republik Indonesia No. 36 Tahun 2009 Tentang Kesehatan. Presiden Republik Indonesia, Jakarta. 2009.

2. Kassebaum N, Bernabé E, Dahiya M, Bhandari B, Murray C, Marcenes W. Global burden of untreated caries: a systematic review and metaregression. Journal of dental research. 2015;94(5):650-8.

3. Indonesia KKDJB, Kesehatan U. Rencana Aksi Nasional Pelayanan Kesehatan Gigi dan Mulut Tahun 20152019. 2015.

4. Sulistyowati M. The Implementation Of School Health Program At Surabaya District, Indonesia. International Journal of Public Health and Clinical Sciences. 2018;5(4):151-60.

5. Felina MM, Gustin RRK, Nurfatimah FF. Gambaran Pelaksanaan Uks (Usaha Kesehatan Sekolah) Dalam Pemberian Informasi Kesehatan Reproduksi Terhadap Siswa MTSN 1 Bonjol Kabupaten Pasaman Tahun 2015. Jurnal Kesehatan. 2016;7(1).

6. Candrawati E, Widiani E. Pelaksanaan Program UKS dengan Perilaku Hidup Bersih dan Sehat (PHBS) Siswa Sekolah Dasar di Kecamatan Kedung Kandang Kota Malang. Care: Jurnal Ilmiah Ilmu Kesehatan. 2015;3(1):15-23.

7. Bekti Prasetyo Y. Pelaksanaan Program Usaha Kesehatan Sekolah Dalam Upaya Meningkatkan Derajat Kesehatan Pada Anak Usia Sekolah Dasar Di Lombok Timur. YARSI medical Journal. 2017;22(2):102-113.

8. Keluarga DK. Pedoman Akselerasi Pembinaan dan Pelaksana UKS. Direktorat Kesehatan Keluarga2016.

9. Nurhayu MA, Shaluhiyah Z, Indraswari R. Pelaksanaan Trias Usaha Kesehatan Sekolah Pada Tingkat Sekolah Dasar Di Wilayah Kecamatan Tembalang Kota Semarang. Jurnal Kesehatan Masyarakat (e-Journal). 2018;6(1):770-9.

10. Government of Pakistan I. School Health Programme: A Strategic Approach for
Improving Health and Education in Pakistan. Islamabad2010.

11. Sukmadinata NS. Metode Penelitian Pendidikan. PT Remaja Rosdakarya: Bandung; 2013.

12. Yuniati S. Perangkat Pembelajaran Matematika Terintegrasi KarakterKeislaman Melalui Pendekatan Kontekstual di Propinsi Riau. MaPan: Jurnal Matematika dan Pembelajaran. 2018;6(1).

13. Hidayah N. Pengembangan Perangkat Pembelajaran Berbasis Subject Specific Pedagogy (SSP) Terintegrasi Pendidikan Karakter dan Revolusi Mental untuk SD/MI di Bandarlampung. Jurnal pendidikan dasar. 2018;2(1):52-66.

14. Trishandra J. Tinjauan Pelaksanaan Usaha Kesehatan Sekolah di SD Negeri 159/III Semumu Kecamatan Depati VII Kabupaten Kerinci. Ensiklopedia of Journal. 2019;1(3).

15. Nasional DP. Pedoman Pelaksanaan UKS di Sekolah. Jakarta: Direktorat Pendidikan Dasar. 2014.

16. Kementrian Kesehatan R. Pedoman Usaha Kesehatan Gigi Sekolah di SMP dan SMA atau yang Sederajat. Jakarta: Kementerian Kesehatan RI; 2012.

17. Rahardjo A, Maharani DA. A Review of Indonesia's Dental Health-Past, Present and Future. Int $\mathbf{J}$ Clin Prev Dent. 2014;10:121-126.

18. Hermien Nugraheni TW, Lanny Sunarjo. Survei Kepuasan Terhadap Layanan Usaha Kesehatan Gigi Sekolah (UKGS). Jurnal Kesehatan Gigi. 2018;2(8):38-46.

19. Santoso B, Sutomo B. Penyuluhan Metode Audio Visual Dan Demonstrasi Terhadap Pengetahuan Menyikat Gigi Pada Anak Sekolah Dasar. Jurnal Kesehatan Gigi. 2016;3(2):53-7.

20. Junaidi J, Razi P. The Implementation Of Oral And Dental Care Services Program Toward Dental Health Status In Elementary School 134/IV Jambi City. Jurnal Kesehatan Gigi. 2018;5(1):1-7. 